\title{
Memory Fragmentation in Dissociative Identity Disorder
}

\author{
Onno van der Hart, $\mathrm{PhD}$ \\ Hilde Bolt, MA \\ Bessel A. van der Kolk, MD
}

\begin{abstract}
This study examined the quality of self-reported memories of traumatic experiences in participants with dissociative identity disorder (DID) and compared them with their memories of non-traumatic, but emotionally significant life experiences. Systematic interview data were gathered from 30 DID patients in The Netherlands. All participants reported a history of severe childhood abuse; $93.3 \%$ reported some period of amnesia for the index traumatic event, and $33.3 \%$ reported periods of amnesia for significant non-traumatic childhood experiences. All participants who had been amnestic for their trauma reported that their memories were initially retrieved in the form of somatosensory flashbacks. This suggests that, like PTSD patients, DID patients at least initially recall their trauma not as a narrative, but as somatosensory re-experiencing. Surprisingly, however, DID participants also recalled emotionally charged non-traumatic life events with significant somatosensory components, a phenomenon that has not been previously reported. This finding raises important issues regarding basic memory processing abnormalities in DID patients. [Article copies available for a fee from The Haworth Document Delivery Service: 1-800-HAWORTH. E-mail address: <docdelivery@haworthpress.com> Website: <http://www.HaworthPress. com> (C) 2005 by The Haworth Press, Inc. All rights reserved.]
\end{abstract}

Onno van der Hart, Professor of Psychopathology of Chronic Traumatization, and Hilde Bolt, Clinical Psychologist, are affiliated with the Department of Clinical Psychology, Utrecht University, The Netherlands.

Bessel A. van der Kolk is Professor of Psychiatry at Boston University and Medical Director of the Trauma Center, Human Resources Institute, Boston, Massachusetts.

Address correspondence to: Onno van der Hart, PhD, Department of Clinical Psychology, Utrecht University, Heidelberglaan 1, 3584 CS Utrecht, The Netherlands (E-mail: o.vanderhart@fss.uu.nl).

Journal of Trauma \& Dissociation, Vol. 6(1) 2005

http://www.haworthpress.com/web/JTD

(c) 2005 by The Haworth Press, Inc. All rights reserved.

Digital Object Identifier: 10.1300/J229v06n01_04 
KEYWORDS. Memory, dissociative amnesia, flashbacks, hippocampus, dissociative identity disorder

\section{INTRODUCTION}

For more than a century clinical observations have been reported that, contrary to memories of non-traumatic events, the initial recall of traumatic events occurs in a fragmentary, sensorimotor, and affective way, often without presence of a clear narrative (Brett \& Ostroff, 1985; Foa, Molnar, \& Cashman, 1995; Janet, 1889, 1928; Myers, 1940; Van der Hart \& Op den Velde, 1991; Van der Kolk \& Van der Hart, 1991). These observations have been confirmed by several systematic exploratory studies. Using the Traumatic Memory Inventory (TMI; Van der Kolk, 1990), Van der Kolk and Fisler (1995) first studied the quality of the memories of traumatic events compared with emotionally significant but non-traumatic events in 46 participants with posttraumatic stress disorder (PTSD). In contrast with memories of non-traumatic events, memories of trauma initially were fragmented. They occurred as waves of intense feelings, and as visual images, olfactory, auditory perceptions, and bodily sensations. With passage of time participants gradually constructed a narrative of what had happened to them that could properly be called an autobiographical memory. Similar findings have been found in other populations such as adult survivors of physical and/or sexual assault (Cameron, 1996, 2000; Nijenhuis, Van Engen, Kusters, \& Van der Hart, 2001; Roe \& Schwartz, 1996; Van der Kolk, Burbridge, \& Suzuki, 1997), and people with "awareness" during anesthesia (Van der Kolk, Hopper, \& Osterman, 2001).

The present study sought to systematically study the recall of traumatic events and of non-traumatic, but emotional significant, events in women with dissociative identity disorder (DID). Retrospective studies consistently have found that DID is strongly correlated with chronic and severe childhood traumatization, in particular childhood sexual and physical abuse (Boon \& Draijer, 1993; Nijenhuis, Spinhoven, Van Dyck, Van der Hart \& Vanderlinden, 1998; Putnam, Guroff, Silberman, Barban, \& Post, 1986; Ross, Norton, \& Wozney, 1989; Saxe et al., 1993; Schultz, Braun, \& Kluft, 1989). These findings are supported by studies using external corroboration of the reported abuse (Coons, 1994; Hornstein \& Putnam, 1992; Kluft, 1995, 1997; Lewis, Yaeger, Swica, Pincus, \& Lewis, 1997; Martínez-Taboas, 1996). 
In a preliminary study of eight female DID participants Bolt (1995) found that, in addition to reporting that their traumatic memories returned as fragments, as had been previously demonstrated in PTSD (e.g., Van der Kolk \& Fisler, 1995), three participants also recalled non-traumatic memories as sensorimotor fragments, e.g., as vivid images, smells, or physical sensations. The primary aim of this study was to explore how people with DID recall traumatic and non-traumatic events, using a larger sample of participants. This study examined how women with a DSM-IV diagnosis of DID experience the quality of their memories for traumatic events compared with those of non-traumatic events.

\section{METHOD}

\section{Participants}

Participants were recruited from clinicians treating patients who met DSM-IV criteria for DID (APA, 1994) in outpatient centers, day hospitals, and psychiatric hospitals in the Netherlands and whose clinicians judged them to be able to comply with the demands of this study. The participants came from 17 different treatment centers and 18 different therapists, all trained and experienced in the treatment of dissociative disorders.

Thirty female participants (mean age $=38.5$ years; $S D=9.8$; range 22-59) were recruited. Ten (33\%) were married or lived with a partner, five $(16.6 \%)$ were divorced, one was widowed (3.3\%), and $14(46.2 \%)$ were single. Twenty-five participants $(84.3 \%)$ were in outpatient treatment, one $(3.3 \%)$ was in day hospital treatment, and four $(13.3 \%)$ were in an inpatient setting. The average duration of the participants' current treatment was 3.0 years $(S D=2.04$; range $0.3-9)$.

\section{Instruments}

Dissociative Experiences Scale (DES; Bernstein \& Putnam, 1986). The DES is a 28 -item self-report questionnaire assessing the frequency of dissociative and absorption experiences in the daily lives of participants. The scores range from 0 to 100. The DES has adequate test-retest reliability, good internal consistency, and good clinical validity (Bernstein \& Putnam, 1986; Carlson et al., 1993). 
Childhood Experiences Questionnaire (CEQ; Draijer, 1989). The CEQ is a structured interview to identify childhood sexual abuse (CSA) and childhood physical abuse (CPA) (Draijer, 1989). Using Draijer's (1988) criteria for the reported degree of severity, a severity-index can be made for both forms of abuse $(0=$ not reported; $1=$ light; $2=$ medium; 3 = serious or very serious).

Traumatic Memory Inventory (TMI; Van der Kolk, 1990; Dutch translation and adaptation, Bolt \& Van der Hart, 1994). The TMI is a 60 -item structured interview that systematically collects data concerning the circumstances and means of memory retrieval of a target traumatic event and a target memory of an emotionally significant but non-traumatic event. The TMI interview inquires about (1) nature of the trauma/event, (2) duration, (3) the past and current awareness of the target trauma/event-and when applicable-when and where the participant became aware that the trauma/event had occurred; (4) circumstances under which the participant initially and currently experienced intrusive memories; (5) modalities in which memories were experienced, e.g., as a story, an image, sounds, smells, bodily feelings, and emotions. In contrast to the Van der Kolk and Fisler (1995) study, in which participants were asked to retrospectively recall how memories were retrieved at three different points in time, i.e., initially, when the participant was most bothered by the memory, and currently, this study focused solely on initial and current retrieval. The TMI also inquires about (6) nature of flashbacks, (7) nature of nightmares, (8) precipitants of flashbacks and nightmares, (9) ways of avoiding intrusive recollections (e.g., by eating, working, taking drugs or alcohol, cleaning, etc.), and (10) independent corroboration of the traumatic event through court or hospital records, direct witnesses, or other means. Participants were asked to identify a specific memory of a traumatic event or series of related traumatic events to serve as the index for further questions. Similarly, they were asked to identify an emotionally significant but non-traumatic event or a series of related events. Following Van der Kolk and Fisler's (1995) procedure, all information was collected first for the traumatic event, then for the non-traumatic event.

\section{Procedure}

After written informed consent was obtained, the participants were interviewed at their treatment centers for approximately 2.5 hours in addition to completing the DES. The participants were told that the aim of the study was to understand how people remember life events. 


\section{Data Analysis}

A non-parametric related samples test, the sign-test, was applied to compare dichotomous scores regarding memories for trauma and memories for non-traumatic childhood events. The relationships among variables of interval level were measured using Pearson's product moment correlation coefficient.

\section{RESULTS}

\section{Abuse History}

All 30 participants reported childhood abuse. Twenty-eight (93.3\%) reported childhood sexual abuse (CSA) and 28 (93.3\%) reported childhood physical abuse (CPA), and 26 (86.7\%) reported both types of abuse. The mean age at which CSA reportedly started was 3.6 years $(S D=$ 2.48 , range 0.3-9 yrs) with an average duration of 10.25 years $(S D=7.4$, range 1-33). The mean age at which CPA reportedly started was 5.1 years $(S D=3.37$, range $0-13)$ with an average duration of 12.5 years $(S D=6.24$, range $3-32)$. Only two $(6.6 \%)$ participants reported that they had told somebody about their sexual abuse during their childhood.

Twenty-one participants (70\%) reported sexual revictimization after age 16 , whereas 15 participants $(50 \%)$ reported repeated physical abuse.

\section{Dissociation}

The mean DES score was $49.2(S D=19.5$; range 9.8-86.5). DES scores were significantly correlated with (1) severity of CSA $(r=.63, p$ $<.0001)$, (2) duration of CSA $(r=.45, p<.015)$, and (3) duration of CPA $(r=.40, p<.033)$. Dissociation was not significantly correlated with severity of CPA, age of onset of either CSA or CPA, or the degree of forgetting the target traumatic event.

\section{Memory of the Traumatic Event}

Twenty-eight participants $(93.3 \%)$ were able to relate a detailed memory of childhood sexual, physical, or emotional abuse. Two participants $(6.6 \%)$ who were unable to relate a detailed memory of a traumatic event before age 16 , chose as the traumatic memory a period of physical abuse after age 16 with a domestic partner as perpetrator (see Table 1). 
Amnesia. Twenty-seven participants $(93.1 \%)$ reported having been unable to recall the index traumatic event for a substantial period of time, even if somebody would have asked them directly about it. A substantial number of participants also reported amnesia for the index non-traumatic event $(N=10 ; 34.5 \%$; Sign test, $p$ (1-tailed) $<0.0001)$. Three participants (10\%) reported that they had no access to both the traumatic and non-traumatic event for an extended period of time, thus suggesting extended periods of global amnesia.

The TMI does not distinguish between the inability to recall parts of the traumatic event and the inability to recall the trauma as a whole. However, two participants volunteered that they had no memory for significant parts of the trauma, rather than the event as a whole:

I have always known the beginning and the end, but the piece in the middle was completely missing. I knew that I lay naked on the bed afterwards, but what had happened before?

I have always known that I went on a vacation, and I always suspected that something was wrong with that vacation. Somewhere very far away you know that. Certain terrible details were completely missing.

There has been a time during which I did know that something like that had happened, but absolutely not its extent. I thought that I was thrown on the ground and that a boy was lying on top of me. And something more and something with a woman next door. Further nothing had happened, I thought.

Confirmation. Nineteen (67.5\%) of the 28 participants who had not recalled the target traumatic event for some period of time reported having found external corroboration for their memories, as had the two participants who reported continuous memories of the trauma (i.e., 63\% altogether). This corroborative evidence was found in letters, diaries, medical files, and by questioning family members. Four participants $(13.3 \%)$ reported having been unable to find corroboration, and 5 (16.6\%) reported not having looked for it.

Reactivating Stimuli. Triggers that precipitated the recall of the traumatic event included (a) therapy $(N=12,38.6 \%)$, (b) television $(N=8)$, (c) a sensation such as tasting certain foods, the smell of sweat, seeing one's own hands move, sexual sensations, etc. $(N=8)$, (d) talking with 
TABLE 1. Reported Memories of Traumatic Events and Non-Traumatic Events

\begin{tabular}{|c|c|c|c|}
\hline Traumatic event & Number & Non-traumatic event & Number \\
\hline Sexual abuse (period or specific event) & 21 & Vacation, on a journey & 10 \\
\hline Physical abuse & 4 & Compliment from an adult & 3 \\
\hline $\begin{array}{l}\text { Emotional abuse, e.g., being locked up } \\
\text { in a closet }\end{array}$ & 3 & $\begin{array}{l}\text { Contact with a friendly adult, } \\
\text { usually a teacher }\end{array}$ & 6 \\
\hline Sent away to an institution & 1 & Birth of twin sisters & 1 \\
\hline \multirow[t]{3}{*}{$\begin{array}{l}\text { During war, ordered to point a gun at } \\
\text { mother }\end{array}$} & 1 & $\begin{array}{l}\text { Experiencing something } \\
\text { pleasant or special with a } \\
\text { family member }\end{array}$ & 8 \\
\hline & & $\begin{array}{l}\text { Others, e.g., winning a price } \\
\text { in a lottery }\end{array}$ & 2 \\
\hline & $N=30$ & & $N=30$ \\
\hline
\end{tabular}

others $(N=7)$, (e) a special day $(N=4)$. The following statements made by two participants illustrate how forgotten memories were retrieved:

On my mother's 60th birthday I was admitted for the first time to a psychiatric inpatient unit. This admission, and my mother's subsequent angry reaction to it, caused the memory to be reactivated. The memory consisted of a color image. Just like a movie, really. ... It happened during a therapy session. ... I had a session and became suddenly terrified of hands. I was talking and I moved my hand, and I suddenly couldn't move my own hand anymore. Then the memory flashed into my mind: my father trying to strangle me. ... It came back as an image: that is why I was very frightened of hands and very frightened of knives.

Initial Quality of Recalling the Traumatic Event. Among the 28 participants who had not recalled the target traumatic event for some time, none recalled this event initially as a story. Rather, all of them re-experienced it along one or more sensory dimensions, with or without associated emotions: in the form of visual images $(N=15)$, affective reliving $(N=17)$, auditory reliving $(N=13)$, kinesthetic reliving $(N=9)$, somatic sensations or physiological reactions $(N=9)$, as a smell $(N=6)$, and as a taste $(N=3)$. Flashback-like images were usually reported "images," without any related narrative. Frequently reported combinations were visual and/or auditory or affective reliving, and auditory/affective reliving. In summary, all participants reported that initial recall occurred as a sensorimotor experience. 
Current Quality of Recalling the Traumatic Event. The most frequently reported current reactivating stimuli were: therapy $(N=9)$, talking with others $(N=9)$, and television programs $(N=17)$. In comparison with initial recall of the index traumatic event, current recall was more often reactivated by physical sensations (Sign-test; $p(1$-tailed) $<0.002)$ or by watching television (Sign-test; $p(1$-tailed) $<0.011)$. Fourteen participants currently reported recalling the traumatic event as a story of what had happened to them; seven reported recalling the memory without accompanying affect, and seven with affect. However, the participants reported that neither the narrative memory with affect and those without were experienced as an integrated autobiographical memory. The following statements are illustrative:

It is not a personal memory, it is simply a fact; emotionless.

It has become now more of a story, but it still doesn't feel as mine. I always have the feeling that the memory develops spontaneously, without my having any influence on it.

When I have the memory, it is still not mine, or it belongs to somebody else, to an alter.

The participants who reported experiencing the memory as a personal narrative with appropriate affect also reported flashbacks:

In the beginning I didn't know what I heard or what I saw. By dreaming and by allowing those memories to come up, they gradually became a story. And that story remained unaltered. When I think of this story, I suffer again from the sounds, emotions, and images.

Only one participant reported having control over the memory of the traumatic event. In her case, the memory seemed to exclusively have an autobiographical narrative character only.

Most participants (93.3\%) reported that the memory of the traumatic event had become more complete over time. However, in the majority of cases $(N=16 ; 53.3 \%)$, the memory of the trauma still returned in a fragmented way. In comparison to initial trauma recall, currently more sensory dimensions were involved. Five participants (16.5\%) reported that their recall occurred in all sensory dimensions. 


\section{Memory of the Non-Traumatic Event}

Participants chose emotionally significant but non-traumatic experiences such as a vacation or trip, receiving a compliment from an adult, contact with a friendly adult, birth of twin-sisters, experiencing something pleasant, winning a prize in a lottery.

Many participants experienced difficulties in recalling a personally emotional but non-traumatic event because they mentioned that they remembered little from their past (Table 1).

Initial Recall of the Non-Traumatic Event. Of the ten participants who, for some length of time, had been unable to recall the target non-traumatic event, three participants recalled this event initially as a narrative, and two participants as affectively charged sensorimotor experiences, predominantly visual images and sounds. Precipitants of the memories of the non-traumatic event included talking with others, therapy, a combination of things, or an emotion.

Current Quality of Recalling the Non-Traumatic Event. The majority of participants $(N=18 ; 60 \%)$ currently also reported recalling their non-traumatic event (see Table 1) as sensory fragments rather than as a narrative. At the time of the interview, 12 participants (40\%) recalled the event as a narrative, and all but one of these experienced the memory as an autobiographical narrative with appropriate affective coloration.

One participant spontaneously commented on the difference in duration between memories of traumatic events and memories of non-traumatic events:

You remember these nice things and you laugh a bit about them ... while those bad memories sometimes haunt you for days.

\section{DISCUSSION}

In this sample of DID patients both the memory of the traumatic event and of the memory of a non-traumatic event returned initially as sensory fragments, short of a clear autobiographical narrative. In the course of time, more sensory dimensions became involved, but this applied more to the memory of the traumatic event. When the traumatic memory evolved into a narrative, in all cases but one, the memory remained depersonalized. The non-traumatic event usually had become more a personal event of the distant past. 


\section{Amnesia for Traumatic and Non-Traumatic Events}

An inability to recall important personal information, too extensive to be explained by ordinary forgetfulness, is a basic feature of the DSM-IV diagnostic category of Dissociative Identity Disorder (APA, 1994). The current findings confirm that among DID patients amnesia is common in one or more childhood traumatic events. This also supports the findings of a large number of retrospective and longitudinal research studies about delayed recall of childhood sexual abuse. The proportion of participants reporting delayed memories of their abuse $(93.7 \%)$ is extremely high. In previous publications, rates of delayed recall have ranged from 19\% to $82 \%$ (Brown, Scheflin, \& Hammond, 1998). However, it should be noted that these publications pertain to delayed memories of any experience of abuse-not of one particular traumatic event, as was the case in this study. We don't know whether our participants would have had continuous recall for other traumatic experiences.

Loftus, Polonsky, and Fullilove (1994) have suggested that in most studies on delayed recall of abuse, participants were not asked if they could not remember the event even if somebody would have asked about it. Thus, Loftus et al. argued that the reported degrees of "amnesia" did not necessarily reflect true amnesia, but were related to false positives due to shame or denial. In this study we included the recommended question concerning remembering if asked about it in the interviews and still found an extremely very high degree of reported amnesia.

\section{The Fragmentary Recall of Memories}

This study with DID participants, in conjunction with a pilot study (Bolt, 1995), confirmed the previously reported phenomenon of initial fragmentary sensorimotor and affective recall of traumatic events (Van der Kolk \& Fisler, 1995; Van der Kolk et al., 1997, 2001). Van der Kolk and Fisler (1995) found that, over time and with increasing awareness of various sensory dimensions of the memory, participants reported beginning to be able to construct a narrative that can properly be called a "memory." In this study, DID participants also reported gradually evolving narratives, but this development did not necessarily mean that participants felt that the abuse was something that had happened to them personally at some particular point in their pasts. Van der Kolk and Fisler's (1995) PTSD participants developed a complete narrative memory of trauma far more frequently than did our participants $(89.1 \%$ vs. 
$45.6 \%)$. This suggests that for DID participants find it difficult to construct an autobiographical/narrative memory of a traumatic childhood event and integrating this memory.

This study is the first to report fragmented initial recall of emotionally significant but non-traumatic events among DID patients. PTSD patients have not previously been reported to recall emotional yet ordinary events at a sensorimotor level, even when questioned in detail about their personal experience of recall. This would suggest that there are fundamental problems with the integration of sensory input into one's autobiography in DID, as is manifested in its core symptom, i.e., "the presence of two or more distinct identities or personality states" (APA, 1994, p. 487).

Several components of the central nervous system are involved in the integration and transformation of sensory input into "memory," i.e., an explicit narrative of the event. Most prominent among these are the parietal association areas, the thalamus, and the hippocampus (Van der Kolk, 2003). The thalamus has recently been shown to play a role in the maintenance of trauma-related dissociation (Lanius et al., 2004). The hippocampus is also involved in the categorization and integration of sensory input (Squire, 1992; O'Keefe \& Nadel, 1978). A decrease in hippocampal volume in women with documented childhood histories of sexual abuse has been well-documented (Bremner et al., 1997; Stein, Koverola, Torchia, \& McClarty, 1997; Teicher, Anderson, \& Polcari, 2002). One of the functions of the hippocampus is to aggregate somatic, affective, and physiological components of experience into one integrated autobiographical memory (O'Keefe \& Nadel, 1978). The hippocampus plays a role in creating spatial and temporal representations of experience, but it is also involved in laying down procedural and emotional memories (Davidson, 2000). Stress-related release of corticosterone can disrupt hippocampal activity, thereby interfering with the capacity to integrate, localize, and categorize experiences (McEwan, De Kloet, \& Rostene, 1986). This could result in the imprints of experience remaining isolated, temporally disordered, and stimulus-bound (Van der Kolk, 1994).

It is likely that the hippocampus plays a central role in the integration of sensory imprints into a narrative that we call "autobiographical memory," which can be disrupted during states of extreme stress. It is possible that in adults with hippocampal damage associated with childhood trauma even mildly arousing information might interfere with the integration of sensory information into an autobiographical narrative. Recent studies by Nijenhuis, Ehling, and Krikke (2002; cf. Nijenhuis, 
2003) support the hypotheses that there are positive associations between hippocampal shrinkage and the severity of dissociation, as well as the reported degree of traumatization. Hippocampal volume was strongly correlated with somatoform and psychoform dissociation, posttraumatic stress symptoms, and cumulative trauma reporting. Patients with DID had about 25\% smaller bilateral hippocampal volume, and patients with DDNOS about 14\% smaller bilateral volume compared to healthy controls.

To date, only a single study has been performed that specifically addresses the relationship between hippocampal volume and autobiographical memory. Stein et al. (1997) found smaller left-sided hippocampal volume for women reporting childhood sexual abuse compared to controls, with volume correlating strongly $(r=-.73)$ with dissociative symptom severity, but not with indices of explicit memory functioning. Thus, it seems that the relationship between hippocampal volume and memory functioning may be mediated by dissociation.

\section{Limitations}

Based upon clinical observations and questioning, the participants were diagnosed by experienced clinicians as DID according to DSM-IV criteria. Although some of these clinicians used the Structured Clinical Interview for DSM-IV Dissociative Disorders (SCID-D; Steinberg, 1994; Dutch version validated by Boon \& Draijer, 1993) as a diagnostic instrument, no systematic independent confirmation of the clinical diagnoses was obtained. However, the mean DES score (49.2) of our participants was quite similar to the result of another study among participants with DID (mean 49.4) in which the SCID-D was used (Boon \& Draijer, 1995). One participant had a score of 9.8 on the DES, raising questions about a true diagnosis of DID. However, Boon and Draijer (1993) described other participants with low DES scores who, following a careful SCID-D interview, eventually were diagnosed with DID.

Given the small sample size $(N=30)$, the findings reported in this study may not be generalizable to all DID patients. In order to more properly evaluate these findings, future studies would require a control group. Another limitation pertains to the selection of the memory of a traumatic event or series of related traumatic events to serve as the index for further questions. We assumed that this memory was prototypical, but the representativeness of that memory for each participant remains unclear. Many TMI items have a multiple choice format. It remains questionable to what degree the responses to these items are influenced 
by demand characteristics. The TMI requires that, during a single interview, participants retrospectively recall how their memories were retrieved at three points in time. It is likely that considerable blurring occurs across the three different times, making comparisons over time unreliable. However, short of prospective studies of severely abused children over several decades (which would affect memory recall itself), retrospective accounts can be the only basis for preliminary studies of a participant that is significant both for clinical care and basic science.

\section{CONCLUSION}

This study documents that the memories of traumatic experiences in patients with DID return initially as sensorimotor fragments, encompass more sensory dimensions over time, and gradually acquire a narrative component, which does not necessarily become "personalized." Compared with PTSD patients, the development of a narrative memory seems to proceed more slowly in DID participants. Contrary to PTSD patients, DID patients may also have amnesia for emotionally significant but non-traumatic events. Memories for these events also tend to be retrieved in fragments in most cases, but the sensorimotor component (re-experiences, dreams/nightmares, and intrusive thoughts) is less pronounced than in traumatic memories.

\section{REFERENCES}

American Psychiatric Association. (1994). Diagnostic and statistical manual of mental disorders, ed. 4. Washington, DC: Author.

Bernstein, E. M., \& Putnam, F. W. (1986). Development, reliability, and validity of a dissociation scale. Journal of Nervous Mental Disease, 174, 727-735.

Bolt, H. (1995). De aard van traumatische herinneringen en niet-traumatische herinneringen bij mensen met een dissociatieve identiteitsstoornis [The nature of traumatic and non-traumatic memories in people with dissociative identity disorder]. Amsterdam: Vrije Universiteit (unpublished master's thesis).

Bolt, H., \& Van der Hart, O. (1994). Traumatic Memory Inventory; Dutch edition. Utrecht: Department of Clinical Psychology, Utrecht University (unpublished report).

Boon, S., \& Draijer, N. (1993). Multiple personality disorder in the Netherlands: A study on reliability and validity of the diagnosis. Lisse: Swets \& Zeitlinger.

Boon, S., \& Draijer, N. (1995). Screening en diagnostiek van dissociatieve stoornissen [Screening and diagnostics of dissociative disorders]. Lisse: Swets \& Zeitlinger. 
Bremner, J. D., Randall, P., Vermetten, E., Staib, L., Bronen, R. A., Mazure, C., Capelli, S., McCarthy, G., Innis, R. B., \& Charney, D. S. (1997). Magnetic resonance imaging-based measurement of hippocampal volume in posttraumatic stress disorder related to childhood physical and sexual abuse: A preliminary report. Biological Psychiatry, 41, 23-32.

Brett, E. A., \& Ostroff, V. (1985). Imagery and post-traumatic stress disorder. American Journal of Psychiatry, 142, 417-424.

Brown, D., Scheflin, A. W., \& Hammond, D. C. (1998). Memory, trauma treatment, and the law. New York: Norton.

Cameron, C. (1996). Comparing amnestic and nonamnestic survivors of childhood sexual abuse: A longitudinal study. In K. Pezdek \& W. P. Banks (Eds.), The recovered/false memory debate (pp. 41-68). San Diego: Academic Press.

Cameron, C. (2000). Resolving childhood trauma: A long-term study of abuse survivors. Thousand Oaks, CA: Sage Publications.

Coons, P.M. (1994). Confirmation of childhood abuse in child and adolescent cases of multiple personality disorder and dissociative disorder not otherwise specified. Journal of Nervous and Mental Disease, 182, 461-464.

Carlson, E. B., Putnam, F. W., Ross, C. A., Torem, M., Coons, P., Dill, D. L., Loewenstein, R. J., \& Braun, B. G. (1993). Validity of the Dissociative Experiences Scale in screening for multiple personality disorder: A multicenter study. American Journal of Psychiatry, 150, 1030-1036.

Davidson, R. J. (2000). Affective style, mood, and anxiety disorders: An affective neuroscience approach. In R. J. Davidson (Ed.), Anxiety, depression, and emotion: The First Wisconsin Symposium on Emotion (pp. 68-108). New York: Oxford University Press.

Draijer, N. (1988). Seksueel misbruik van meisjes door verwanten [Sexual abuse of girls by relatives]. Den Haag: Ministerie van Sociale Zaken en Werkgelegenheid.

Draijer, N. (1989). Structured Trauma Interview. Delft: Unpublished report.

Foa, E. B., Molnar, C., \& Cashman, L. (1995). Change in rape narratives during exposure therapy for posttraumatic stress disorder. Journal of Traumatic Stress, 8, 675-690.

Hornstein, N. L., \& Putnam, F. W. (1992). Clinical phenomenology of child and adolescent dissociative disorders. Journal of the American Academy of Child and Adolescent Psychiatry, 31, 1077-1085.

Janet, P. (1889). L'Automatisme psychologique [Psychological automatism] Paris: F. Alcan.

Janet, P. (1928). L'Evolution de la mémoire et de la notion du temps [The evolution of memory and of the notion of time]. Paris: A. Chahine.

Kluft, R. P. (1995). The confirmation and disconfirmation of abuse in DID patients: A naturalistic study. Dissociation, 8, 253-258.

Kluft, R. P. (1997). The argument for the reality of delayed recall of trauma. In P.S. Appelbaum, L. A. Uyehara, \& M. R. Elin (Eds.), Trauma and memory: Clinical and legal controversies (pp. 25-57). New York: Oxford University Press.

Lanius, R. A., Williamson, P. C., Densmore, M., Boksman, K., Neufeld, R. W., Gati, J. S., \& Menon, R. S. (2004). The nature of traumatic memories: A 4-T fMRI functional connectivity analysis American Journal of Psychiatry, 161, 36-44. 
Lewis, D. O., Yeager, C. A., Swica, Y., Pincus, J. H., \& Lewis, M. (1997). Objective documentation of child abuse and dissociation in 12 murderers with dissociative identity disorder. American Journal of Psychiatry, 154, 1703-1710.

Loftus, E., Polonsky, S., \& Fullilove, M. T. (1994). Memories of childhood sexual abuse: remembering and repressing. Psychology of Women Quarterly, 18, 67-84.

Martínez-Taboas, A. (1996). Repressed memories: Some clinical data contributing towards its elucidation. American Journal of Psychotherapy, 50, 217-230.

McEwen, B. S., De Kloet, E. R., \& Rostene, W. (1986). Adrenal steroid receptors an actions of the nervous system. Physiological Review, 66, 1121-1188.

Myers, C. S. (1940). Shell shock in France 1914-18. Cambridge: Cambridge University Press.

Nijenhuis, E. R. S. (2003). The importance of studying trauma-related disorders. Newsletter Research Institute for Psychology \& Health, 7(1), 14-17.

Nijenhuis, E. R. S., Ehling, T., \& Krikke, A. (2002). Hippocampal volume in florid and recovered cases of DID, DDNOS, and healthy controls: Three MRI studies. Proceedings of the 19th International Fall Conference of the International Society for the Study of Dissociation (p. 43). Chicago, IL: International Society for the Study of Dissociation.

Nijenhuis, E. R. S., Spinhoven, P., Van Dyck, R., Van der Hart, O., \& Vanderlinden, J. (1998). Degree of somatoform and psychological dissociation is correlated with reported trauma. Journal of Traumatic Stress, 11, 711-728.

Nijenhuis, E. R. S., Van Engen, A., Kusters, I., \& Van der Hart, O. (2001). Peritraumatic somatoform and psychological dissociation in relation to recall of childhood sexual abuse. Journal of Trauma \& Dissociation, 2(3), 49-68.

O'Keefe, J., \& Nadel, L. (1978). The hippocampus as a cognitive map. Oxford: Clarendon Press.

Putnam, F. W., Guroff, J. J., Silberman, E. K., Barban, L., \& Post, R. M. (1986). The clinical phenomenology of multiple personality disorder. Journal of Clinical Psychiatry, 47, 285-293.

Roe, C. M., \& Schwartz, M. (1996). Characteristics of previously forgotten memories of sexual abuse: A descriptive study. Journal of Psychiatry and Law, 24, 189-206.

Ross, C. A., Norton, G. R., \& Wozney, K. (1989). Multiple personality disorder: An analyses of 236 cases. Canadian Journal of Psychiatry, 34, 413-418.

Saxe, G. N., Van der Kolk, B. A., Hall, K., Schwartz, J., Chinman, G., Hall, K., Lieberg, G., \& Berlowitz, R. (1993). Dissociative disorders in psychiatric inpatients. American Journal of Psychiatry, 150, 1037-1042.

Schultz, R., Braun, B. G., \& Kluft, R. P. (1989). Multiple personality disorder: Phenomenology of selected variables in comparison to major depression. Dissociation, 2(1), 45-51.

Squire, L. R. (1992). Memory and the hippocampus: A synthesis from findings with rats, monkeys, and humans. Psychological Review, 92, 195-231.

Stein, M. B., Koverola, C. H. C., Torchia, M. G., \& McClarty, B. (1997). Hippocampal volume in women victimized by childhood sexual abuse. Psychological Medicine, 27, 951-959.

Steinberg, M. (1994). Structured Clinical Interview for DSM-IV Dissociative Disorders (SCID-D). Washington, DC: American Psychiatric Press. 
Teicher, M., Anderson, S., \& Polcari, A. (2002). Developmental neurobiology of childhood stress and trauma. Psychiatric Clinics of North America, 25, 397-426.

Van der Hart, O., \& Op den Velde, W. (1991). Traumatische herinneringen [Traumatic memories]. In O. Van der Hart (Ed.), Trauma Dissociatie en Hypnose (pp. 71-90). Lisse: Swets \& Zeitlinger.

Van der Kolk, B. A. (1990). Traumatic Memory Inventory. Boston: Unpublished report.

Van der Kolk, B. A. (1994). The body keeps the score: Memory and the evolving psychobiology of posttraumatic stress. Harvard Review of Psychiatry, 1, 253-265.

Van der Kolk, B. A. (2003). The neurobiology of childhood trauma and abuse. Child and Adolescent Psychiatric Clinics of North America, 12, 293-317.

Van der Kolk, B. A., \& Fisler, R. (1995). Dissociation and the fragmentary nature of traumatic memories: Overview and exploratory study. Journal of Traumatic Stress, $8,505-525$.

Van der Kolk, B. A., Burbridge, J., \& Suzuki, J. (1997). The psychobiology of traumatic memory: Clinical implications of neuroimaging studies. Annals of the New York Academy of Sciences, 821, 99-113.

Van der Kolk, B. A., Hopper, J., \& Osterman, J. (2001). Exploring the nature of traumatic memories: Combining clinical knowledge with laboratory methods. Journal of Aggression, Maltreatment, and Trauma, 4(2), 9-31.

Van der Kolk, B. A., \& Van der Hart, O. (1991). The intrusive past: The flexibility of memory and the engraving of trauma. American Imago, 48, 425-454.

RECEIVED: 05/05/03

REVISED: 01/26/04

$03 / 10 / 04$

ACCEPTED: 03/10/04 